\title{
The use of throat packs in ear, nose and throat, oral and dental surgery: a systematic review*
}

\author{
Caroline R. Anderson'1, Yaamini Premakumar², Annakan V. Navaratnam³, \\ Maral Rouhani ${ }^{4}$, Arvind Singh ${ }^{3}$ \\ 'The Royal National Throat, Nose and Ear Hospital, 330 Grays Inn Rd, Kings Cross, London, WC1X 8DA, United Kingdom \\ 2Chelsea and Westminster Hospital, 369 Fulham Rd, Chelsea, London SW10 9NH, United Kingdom \\ ${ }^{3}$ Northwick Park Hospital, Watford Rd, Harrow HA1 3UJ, United Kingdom \\ ${ }^{4}$ West Middlesex Hospital, Twickenham Rd, Isleworth TW7 6AF, United Kingdom
}

Rhinology 58: 4, 306 - 313, 2020

https://doi.org/10.4193/Rhin19.308

*Received for publication:

December 16, 2019

Accepted: March 8, 2020

\begin{abstract}
Background: Throat packs are placed around the airway in patients undergoing upper airway surgical procedures under general anaesthetic to prevent aspiration or ingestion of blood, and consequent chest infections or postoperative nausea and vomiting (PONV). There is no definitive evidence for this, and each time a pack is placed, it risks being retained and obstructing the upper airway. This study aimed to determine whether throat packs are of benefit to patients undergoing upper airway surgical procedures.
\end{abstract}

Methods: Medline, Embase and Central were searched from conception to 15th January 2018 using individualised search strategies. A systematic search of multiple databases was undertaken using custom strategies to identify all relevant randomised controlled trials. Screening, risk of bias assessment and data extraction were undertaken independently by two authors. Primary outcomes included throat pain and PONV. Secondary outcomes included any adverse event documented.

Results: Thirteen papers were eligible for inclusion. No studies reported any instances of retained throat packs. Ten studies assessed the effect of throat packs on post-operative throat pain, with four papers showing a significantly higher incidence of pain when throat packs were used. One study showed throat pain to be slightly, but significantly, worse 24 hours post-surgery when a pack was not used. No paper showed throat packs to be of benefit in preventing PONV.

Conclusion: The study was limited by methodological flaws of included trials, overall relatively low numbers of patients and difficulty in contacting authors to clarify information and obtain raw data. However, this systematic review found no evidence to support the use of throat packs. This supports the proposal that there is no indication for the routine use of throat packs in ENT, maxillofacial and dental procedures.

Key words: throat pack, head and neck surgery, PONV

\section{Introduction}

Throat packs are placed around the airway in patients undergoing certain surgical procedures under general anaesthesia ${ }^{(1)}$. They are often in the form of a long piece of gauze material with a radioopaque tag and their role is usually to prevent aspiration or ingestion of fluid, blood or debris during surgery and therefore reduce risk of post-operative respiratory complications as well as nausea and vomiting. Throat packs can also be used to seal the area around the tracheal tube, preventing leakage of anaesthetic gases, or to stabilise a tracheal tube or supraglottic device and prevent its displacement.

There is national and international variation in practice relating to throat pack use; but they are routinely used by some clinicians in the UK in ear, nose and throat (ENT), oral and dental surgery ${ }^{(1,2)}$. Traditionally, placement of throat packs is performed by anaesthetists ${ }^{(2)}$ and surgeons $\mathrm{s}^{(3,4)}$.

The primary disadvantage of throat pack use is the risk of retention post operatively and potential for airway obstruction. 
Despite multiple methods designed to avoid retention ranging from stickers placed on the patient to attaching the pack to the endotracheal tube ${ }^{(5,6)}$ and its classification as a never event ${ }^{(7)}$, there remain multiple documented cases of throat pack retention each year in the UK (15 between 2015-2018) $)^{(7)}$.

A recent UK consensus statement and qualitative systematic review states that anaesthetists should no longer routinely insert throat packs ${ }^{(1)}$. Given that retained throat packs pose significant risks, their benefits need to be shown to outweigh these risks if they are to continue to be used in ENT and oral surgery.

The primary aim of this systematic review is to determine whether throat packs are of benefit to patients undergoing ENT, oral and dental surgery, as compared to no throat pack, in preventing complications associated with blood entering the chest and stomach (i.e. chest infections and post-operative nausea and vomiting).

The secondary aim is to determine whether throat packs cause complications (i.e. oropharyngeal mucosal injury, retained swab, airway compromise), as compared to no throat pack, in patients undergoing ENT, oral and dental surgery.

\section{Methods}

This review was undertaken in line with the 2009 PRISMA guidelines $^{(8)}$ using Cochrane methodology ${ }^{(9)}$. A protocol was written prior to initiation of this review, and is available on Prospero at http://www.crd.york.ac.uk/PROSPERO/display_record. php?ID=CRD42018105436

Medline, Embase and Central were searched from conception to 15th January 2018 using individualised search strategies (Online Appendix 1), with keywords identified from primary studies and guidelines relating to the use of throat packs. There were no limitations placed on year of publication or language. Reference lists of articles obtained from searching, and related reviews and publications were screened for further studies.

The search was limited to randomised controlled trials (RCTs) in humans. To be eligible for inclusion, studies had to compare throat packs of any type to no throat packs, in patients undergoing any ENT, dental or oral surgical procedure. Studies of different designs and non-human studies were excluded. There were no limitations placed on outcome measures. An initial list of outcomes included: post-operative nausea and vomiting, post-operative sore throat, airway displacement, aspiration and retention of packs in the immediate post-operative period.

Two reviewers independently screened titles and abstracts to remove obviously irrelevant reports. Full texts were screened independently by two reviewers for compliance with eligibi-

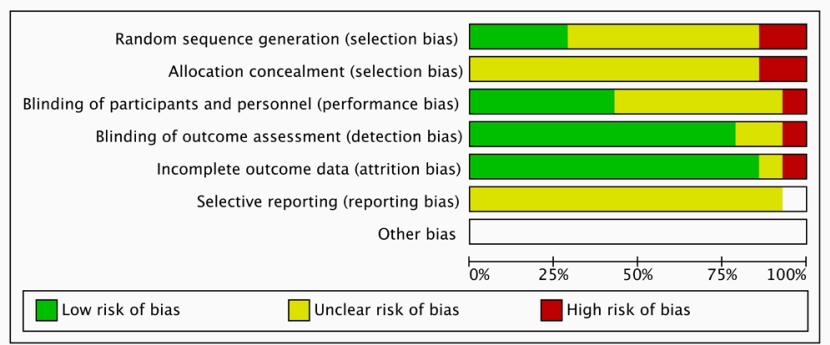

Figure 1. Summary Risk of Bias Data; review authors' judgments about each risk of bias item presented as percentages across all included studies.

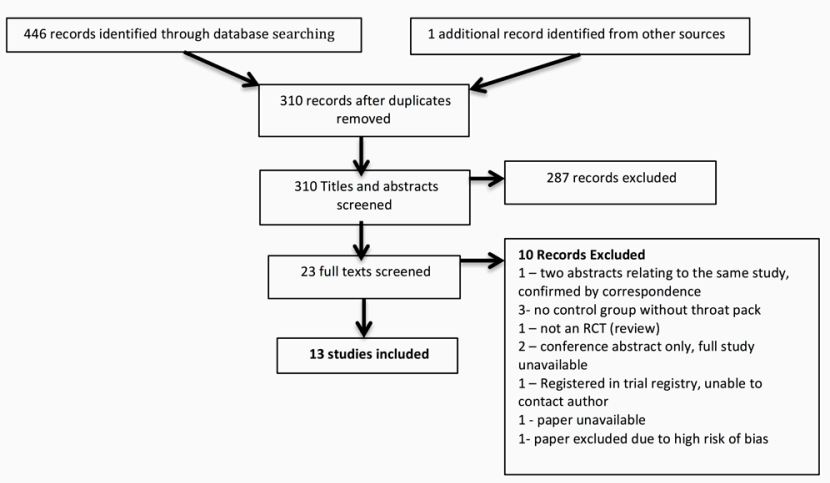

Figure 2. PRISMA flow chart for this review.

lity criteria. Disagreements were resolved by discussion and a third author was consulted where necessary. Studies meeting the inclusion criteria were quality assessed in duplicate by two authors using Cochrane Collaborations 'Risk of Bias' tool(10). Data was extracted from papers independently, in duplicate by two authors using a form designed for this review and piloted prior to full data extraction. Discrepancies in data extraction were resolved by discussion including a third author. Authors of studies were approached to obtain missing data or where clarification was required. Where multiple variations of throat packs or endotracheal tubes were used, the data was collected for each individual group, as well as being simplified to represent single 'packed' groups.

\section{Statistical methods}

Data was handled and analysed using Microsoft Excel version 14.2 for Mac. Meta-analysis was conducted using Review Manager 5.3. Heterogeneity was assessed using 12 statistics. An inverse variance approach was used due to the small sample sizes, and a random effects model was used to take into account between study variations.

\section{Results}

In total 446 records were identified through searching, of which 23 full texts were screened. Fourteen studies were eligible for 
Table 1. Summary of included papers.

\begin{tabular}{|c|c|c|c|c|c|c|}
\hline Study & Country & Surgery & Description of Throat Pack & $\begin{array}{l}\text { Number } \\
\text { in study }\end{array}$ & $\begin{array}{l}\text { Outcome } \\
\text { measures }\end{array}$ & $\begin{array}{l}\text { Significant } \\
\text { Findings }\end{array}$ \\
\hline $\begin{array}{l}\text { Fine et al, } \\
1988\end{array}$ & USA & $\begin{array}{l}\text { Removal of impacted } \\
\text { wisdom teeth }\end{array}$ & Dry gauze pack & 60 & Throat pain & $\begin{array}{l}\text { Pack increases } \\
\text { throat pain }\end{array}$ \\
\hline $\begin{array}{l}\text { Seraj et al, } \\
1991\end{array}$ & Saudi Arabia & $\begin{array}{l}\text { SMR; septorhinoplasty; } \\
\text { nasal polypectomy, } \\
\text { turbinectomy, } \\
\text { antral lavage }\end{array}$ & Wet pack & 40 & $\begin{array}{l}\text { Volume of } \\
\text { secretions sucti- } \\
\text { oned }\end{array}$ & No significant effect \\
\hline $\begin{array}{l}\text { Marais \& Prescott, } \\
1993\end{array}$ & UK & Nasal surgery & $\begin{array}{l}\text { Moist gauze-roll throat } \\
\text { packs or two dry tampons }\end{array}$ & 120 & Throat pain & $\begin{array}{l}\text { Packs increase } \\
\text { throat pain }\end{array}$ \\
\hline $\begin{array}{l}\text { Tay et al, } \\
2002\end{array}$ & Singapore & $\begin{array}{l}\text { Removal of impacted } \\
\text { wisdom teeth }\end{array}$ & $\begin{array}{l}\text { Gauze soaked in sterile } \\
\text { saline }\end{array}$ & 62 & Throat pain & $\begin{array}{l}\text { No significant } \\
\text { effects }\end{array}$ \\
\hline $\begin{array}{l}\text { Basha et al, } \\
2006\end{array}$ & UK & Nasal surgery & $\begin{array}{l}\text { Saline-soaked green } \\
\text { ribbon gauze }\end{array}$ & 93 & $\begin{array}{l}\text { PONV and throat } \\
\text { pain }\end{array}$ & $\begin{array}{l}\text { Pack increases } \\
\text { throat pain }\end{array}$ \\
\hline $\begin{array}{l}\text { Piltcher et al, } \\
2007\end{array}$ & Brazil & $\begin{array}{l}\text { Nasal and/or sinus } \\
\text { surgery }\end{array}$ & Two damp gauzes & 144 & $\begin{array}{l}\text { PONV and throat } \\
\text { pain }\end{array}$ & No significant effect \\
\hline $\begin{array}{l}\text { Erkalp et al, } \\
2010\end{array}$ & Turkey & $\begin{array}{l}\text { Nasal and/or sinus } \\
\text { surgery }\end{array}$ & 'Pharyngeal pack' & 100 & Apthous stomatitis & $\begin{array}{l}\text { Packs increase } \\
\text { apthous stomatitis }\end{array}$ \\
\hline $\begin{array}{l}\text { Korkut et al, } \\
2010\end{array}$ & Turkey & $\begin{array}{l}\text { Nasal and/or sinus } \\
\text { surgery }\end{array}$ & 'Pharyngeal pack' & 100 & PONV & No significant effect \\
\hline $\begin{array}{l}\text { Fennessy et al, } \\
2011\end{array}$ & Ireland & $\begin{array}{l}\text { Septoplasty, rhinoplasty } \\
\text { or ESS }\end{array}$ & Dry or saline soaked gauze & 52 & $\begin{array}{l}\text { PONV and throat } \\
\text { pain }\end{array}$ & No significant effect \\
\hline $\begin{array}{l}\text { Razavi et al, } \\
2015\end{array}$ & Iran & Septorhinoplasty & Saline soaked gauze & 89 & $\begin{array}{l}\text { PONV and throat } \\
\text { pain }\end{array}$ & $\begin{array}{l}\text { Pack increases } \\
\text { severe throat pain }\end{array}$ \\
\hline $\begin{array}{l}\text { Meco et al, } \\
2016\end{array}$ & Turkey & Nasal and ESS & $\begin{array}{l}\text { Cotton packs-dry, soaked } \\
\text { with water, or soaked with } \\
\text { chlorhexidine gluconate } \\
0.2 \% \text { \& benzydamine } \\
\text { hydrochloride } 0.15 \%\end{array}$ & 201 & $\begin{array}{l}\text { PONV and throat } \\
\text { pain }\end{array}$ & No significant effect \\
\hline $\begin{array}{l}\text { Al-Lami et al, } \\
2017\end{array}$ & UK & $\begin{array}{l}\text { ESS, Septoplasty, } \\
\text { Septorhinoplasty, } \\
\text { Turbinate Reduction } \\
\text { Nasal polypectomy }\end{array}$ & $\begin{array}{l}\text { Water-soaked non-sterile } \\
\text { X-ray detectable throat } \\
\text { pack }\end{array}$ & 80 & $\begin{array}{l}\text { PONV and throat } \\
\text { pain }\end{array}$ & $\begin{array}{l}\text { Pack increases } \\
\text { throat pain }\end{array}$ \\
\hline $\begin{array}{l}\text { Green et al, } \\
2017\end{array}$ & USA & ESS & Dry gauze swab & 45 & $\begin{array}{l}\text { PONV and throat } \\
\text { pain }\end{array}$ & $\begin{array}{l}\text { Pack decreases } \\
\text { throat pain }\end{array}$ \\
\hline
\end{tabular}

PONV: post operative nausea and vomiting. ESS: endoscopic sinus surgery. SMR: submucous reduction.

inclusion and were assessed for risk of bias. One study was excluded due to high risk of bias. Summary information is shown in Figure 1. Study inclusion and exclusion was recorded in a flow chart (Figure 2)(8).

The thirteen included papers are summarised in Table 1. The majority of papers included patients undergoing nasal and paranasal sinus surgery and two included patients having dental extractions $\mathbf{s}^{(11,12)}$.

Studies were inconsistent in their reporting of patient demographics but of those that gave full information, all but one $\mathrm{e}^{(12)}$ included more males than females, with mean age ranging from 27 to $50^{(9)}$.

\section{Type and insertion of throat pack}

Included studies used a variety of pharyngeal packs, including gauze swabs ${ }^{(13-17)}$, ribbon gauze ${ }^{(18)}$ and tampons $s^{(13)}$, both wet and dry. One study ${ }^{(19)}$ looked at whether there were differences between dry cotton packs and packs soaked with either water, or chlorhexidine gluconate $0.2 \%$ solution and benzydamine hydrochloride $0.15 \%$ solution, finding no differences. Several studies were not specific about the type of pack used ${ }^{(20-22)}$. For the purpose of this review, packs were considered as a single intervention regardless of type.

The pack was explicitly stated as being inserted by an anaesthetist in five of the included studies. In the remaining eight studies it was implied that this was the case, with the majority describing the insertion of the pack with the description of the anaesthetic technique. In all studies patients were intubated. 
Table 2. Summary of incidence of pain in patients with and without throat packs, at reported time points.

\begin{tabular}{|c|c|c|c|c|c|c|}
\hline \multirow[t]{3}{*}{ Study } & \multirow[t]{3}{*}{ Time point } & \multicolumn{4}{|c|}{ Group } & \multirow[t]{3}{*}{$P$ value } \\
\hline & & \multicolumn{2}{|c|}{ Pack } & \multicolumn{2}{|c|}{ No Pack } & \\
\hline & & Number & $\%$ & Number & $\%$ & \\
\hline Fine et al, 1988 & Overall & $16 / 25$ & 64 & $3 / 35$ & 9 & $<0.05$ \\
\hline \multirow[t]{2}{*}{ Marais \& Prescott, 1993} & $6 \mathrm{hrs}$ & $61 / 80$ & 76 & $20 / 40$ & 50 & $0.004^{*}$ \\
\hline & $24 \mathrm{hrs}$ & $42 / 80$ & 52 & $10 / 40$ & 25 & $0.004^{*}$ \\
\hline \multirow[t]{2}{*}{ Tay et al, 2002} & Recovery & $19 / 26$ & 73 & $28 / 36$ & 78 & 0.9 \\
\hline & $24 \mathrm{hrs}$ & $13 / 26$ & 50 & $20 / 36$ & 56 & 0.86 \\
\hline \multirow[t]{3}{*}{ Basha et al, 2006} & Recovery & $30 / 45$ & 67 & $16 / 48$ & 33 & $0.001^{*}$ \\
\hline & $2 \mathrm{hrs}$ & $42 / 45$ & 93 & $46 / 48$ & 96 & $0.59^{*}$ \\
\hline & $6 \mathrm{hrs}$ & $43 / 45$ & 96 & $42 / 48$ & 88 & $0.166^{*}$ \\
\hline Piltcher et al, 2007 & Overall & $28 / 74$ & 38 & $32 / 70$ & 46 & $0.338^{*}$ \\
\hline \multirow[t]{4}{*}{ Razavi et al, 2015} & Recovery & $17 / 44$ & 39 & $12 / 45$ & 27 & 0.61 \\
\hline & $2 \mathrm{hrs}$ & $14 / 44$ & 32 & $8 / 45$ & 18 & 0.18 \\
\hline & $6 \mathrm{hrs}$ & $7 / 44$ & 16 & $5 / 45$ & 11 & 0.44 \\
\hline & $24 \mathrm{hrs}$ & $14 / 44$ & 32 & $10 / 45$ & 22 & 0.64 \\
\hline
\end{tabular}

${ }^{*} \mathrm{p}$-value calculated for this review using $\mathrm{Chi}^{2}$ test as not available in original paper.

\section{The effect of throat packs on post-operative nausea and vomiting}

Eight studies assessed the effect of throat packs on post-operative nausea and vomiting. Six studies reported the incidence of nausea and/or vomiting at various time points; these results are summarised in Table 3. Basha et al. showed a significant increase in PONV in patients with throat packs during the recovery period, $\mathrm{p}<0.05,-$ an effect that disappeared at 2 and 6 hours ${ }^{(18)}$. No other study showed any significant relationship between throat packs and PONV(14,16,17,19,21).

Six papers also reported severity of PONV, with none showing any relationship between PONV severity and throat pack use $(15,17-19,21,22)$.

All but two studies ${ }^{(20,22)}$ gave intra-operative anti-emesis. Use of anti-emetics post-operatively was variable and variably reported, making it impossible to understand the effect of this on the results.

\section{The effect of throat packs on post-operative throat pain}

Ten studies assessed the effect of throat packs on post-operative throat pain. Overall five studies showed significantly greater inci-

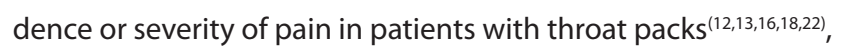
and one showed significantly greater severity of pain in patients without throat packs ${ }^{(17)}$. Four showed no significant difference in pain between patients with and without throat packs ${ }^{(11,14,15,19)}$.
Six studies reported incidence of throat pain at differing time points; these results are summarised in Table 2. Fine et al. showed a significantly higher incidence of pain in the group with throat packs at 24 hours post op ${ }^{(12)}$, a finding replicated by Marais et al. at 6 and 24 hours $^{(13,14)}$. Basha et al. showed the same effect but only in their 'recovery' time point, with the significance lost at 2 and 6 hours ${ }^{(18)}$.

Meta-analysis of studies reporting incidence of post-operative pain showed significantly lower incidence of pain at 6 hours in patients who did not have a throat pack placed (OR 2.63, 95\% $\mathrm{Cl} 1.41$ to 2.91 ), with low heterogeneity at this time point. There was no significant difference between the packed and non-packed groups in recovery, or at 2 or 24 hours, although there was high heterogeneity (Figure 3 ).

Four papers ${ }^{(11,13,16,18)}$ reported severity alongside incidence of pain. The only significant finding was in Razavi et al., who reported a higher number of patients with severe throat pain in the packing group at all studied time points, although no overall difference in the incidence of pain between groups ${ }^{(16)}$.

Four further papers reported only pain severity ${ }^{(15,17,19,22)}$. Fennessey et al. and Meco et al. reported medians of visual analogue scores (VAS), at multiple time points. Neither study found any significant difference in pain severity between patients who did and did not have throat packs ${ }^{(15,19)}$. Al-Lami et al., and Green et al., reported mean severity of pain as measured by VAS and Wong-Baker FACES pain rating scale respectively. Al-Lami et 
Table 3. Summary of incidence of postoperative nausea and vomiting in patients with and without throat packs, at reported time points.

\begin{tabular}{|c|c|c|c|c|c|c|c|}
\hline \multirow[t]{3}{*}{ Study } & \multirow[t]{3}{*}{ Measure } & \multirow[t]{3}{*}{ Time point } & \multicolumn{4}{|c|}{ Group } & \multirow[t]{3}{*}{$P$ value } \\
\hline & & & \multicolumn{2}{|c|}{ Pack } & \multicolumn{2}{|c|}{ No Pack } & \\
\hline & & & Number & $\%$ & Number & $\%$ & \\
\hline \multirow[t]{3}{*}{ Basha et al, 2006} & \multirow[t]{3}{*}{ Nausea \& vomiting } & Recovery & $15 / 45$ & 33 & $7 / 48$ & 15 & $<0.05$ \\
\hline & & $2 \mathrm{hrs}$ & $29 / 45$ & 64 & $32 / 48$ & 67 & $0.051^{*}$ \\
\hline & & $6 \mathrm{hrs}$ & $20 / 45$ & 44 & $27 / 48$ & 56 & $0.25^{*}$ \\
\hline \multirow[t]{2}{*}{ Piltcher et al, 2007} & \multirow{2}{*}{$\begin{array}{l}\text { Vomiting } \\
\text { Nausea }\end{array}$} & Overall & $5 / 74$ & 7 & $10 / 70$ & 14 & $0.14^{*}$ \\
\hline & & Overall & $18 / 74$ & 24 & $14 / 70$ & 20 & $0.39 *$ \\
\hline \multirow[t]{4}{*}{ Korkut et al, 2010} & \multirow[t]{4}{*}{ Nausea \& vomiting } & $2 \mathrm{hrs}$ & $29 / 50$ & 58 & $33 / 50$ & 66 & 0.41 \\
\hline & & $4 \mathrm{hrs}$ & $26 / 50$ & 52 & $23 / 50$ & 46 & 0.54 \\
\hline & & $8 \mathrm{hrs}$ & $17 / 50$ & 34 & $14 / 50$ & 28 & 0.51 \\
\hline & & $24 \mathrm{hrs}$ & $0 / 50$ & 0 & $0 / 50$ & 0 & \\
\hline Razavi et al, 2015 & Nausea \& vomiting & Overall & $8 / 44$ & 18 & $6 / 45$ & 13 & NS \\
\hline \multirow[t]{8}{*}{ Meco et al, 2016} & \multirow[t]{4}{*}{ Nausea } & Recovery & $10 / 151$ & 7 & $5 / 50$ & 10 & $0.43^{*}$ \\
\hline & & $5 \mathrm{mins}$ & $8 / 151$ & 5 & $2 / 50$ & 4 & $0.71^{*}$ \\
\hline & & 10mins & $11 / 151$ & 7 & $1 / 50$ & 2 & $0.17^{*}$ \\
\hline & & $30 \mathrm{mins}$ & $10 / 151$ & 7 & $3 / 50$ & 6 & $0.88^{*}$ \\
\hline & \multirow[t]{4}{*}{ Vomiting } & Recovery & $2 / 151$ & 1 & $0 / 50$ & 0 & $0.41^{*}$ \\
\hline & & $5 \mathrm{mins}$ & $1 / 151$ & 1 & $0 / 50$ & 0 & $0.56^{*}$ \\
\hline & & $10 \mathrm{mins}$ & $1 / 151$ & 1 & $0 / 50$ & 0 & $0.56^{*}$ \\
\hline & & 30 mins & $1 / 151$ & 1 & $1 / 50$ & 2 & $0.41^{*}$ \\
\hline \multirow[t]{3}{*}{ Green et al, 2017} & Vomiting & Overall & $3 / 23$ & 13 & $1 / 23$ & 4 & 0.323 \\
\hline & \multirow[t]{2}{*}{ Nausea } & $4 \mathrm{hrs}$ & $5 / 22$ & 22 & $1 / 23$ & 4 & 0.315 \\
\hline & & $24 \mathrm{hrs}$ & $2 / 23$ & 22 & $1 / 20$ & 4 & 0.323 \\
\hline
\end{tabular}

* $\mathrm{p}$-value calculated for this review using $\mathrm{Chi}^{2}$ test as not available in original paper.

Table 4. Summary of studies reporting outcomes other than pain and PONV.

\begin{tabular}{|c|c|c|c|c|c|c|c|}
\hline \multirow[t]{3}{*}{ Study } & \multirow[t]{3}{*}{ Outcome } & \multirow[t]{3}{*}{ Time point } & \multicolumn{4}{|c|}{ Group } & \multirow[t]{3}{*}{ P value } \\
\hline & & & \multicolumn{2}{|c|}{ Pack } & \multicolumn{2}{|c|}{ No Pack } & \\
\hline & & & Number & $\%$ & Number & $\%$ & \\
\hline Seraj et al, 1991 & Volume of blood suctioned & End of procedure & $1 / 20$ & 5 & $3 / 20$ & 15 & $>0.2$ \\
\hline Erkalp et al, 2010 & Apthous stomatitis & 3 days post op & $12 / 50$ & 24 & $3 / 50$ & 6 & 0.02 \\
\hline Fine et al, 1988 & Hoarse voice & 24 hours post op & $4 / 25$ & 16 & $3 / 35$ & 9 & 0.63 \\
\hline
\end{tabular}

al. reported a significant association between throat pain and throat pack use in the immediate recovery period, $p=0.018$, but this association was not seen at 2 and 6 hours ${ }^{(22)}$. Green et al. found that pain was significantly worse at 24 hours in patients in whom a pack was not used, $\mathrm{p}=0.00217$.

Use of analgesia intra- and post-operatively was inconsistently recorded and reported by the included studies, so was not factored into the results.

\section{The effect of throat packs on aphthous stomatitis}

Erkalp et al reported the presence of aphthous stomatitis at three days post-op. Throat packs were shown to significantly increase the incidence of apthous stomatitis, $p=0.02$ (Table 4) (20). The control group of no throat pack resulted in aphthous ulcers in 3 out of 50 patients on the lateral surface of the tongue and uvula. The throat pack group found aphthous ulcers in 12 out of 50 patients on the lateral surface of the tongue, uvula, soft palate and buccal mucosa.

\section{The effect of throat packs on airway soiling}

Seraj et al assessed airway soiling at the end of the procedure, finding no significant difference in the volume of blood or secretions aspirated from a subglottic port between patients with and without packs, P>0.2 (Table 4) ${ }^{(23)}$. Meco et al. recorded the surgeons' assessment of quantity of bleeding on a qualitative 1-5 scale, again with no differences between groups with and without throat packs ${ }^{(19)}$.

\section{The effect of throat packs on voice hoarseness}

Fine et al reported on the presence of voice hoarseness at 24 hours post- dental surgery by interviewing patients and relying 

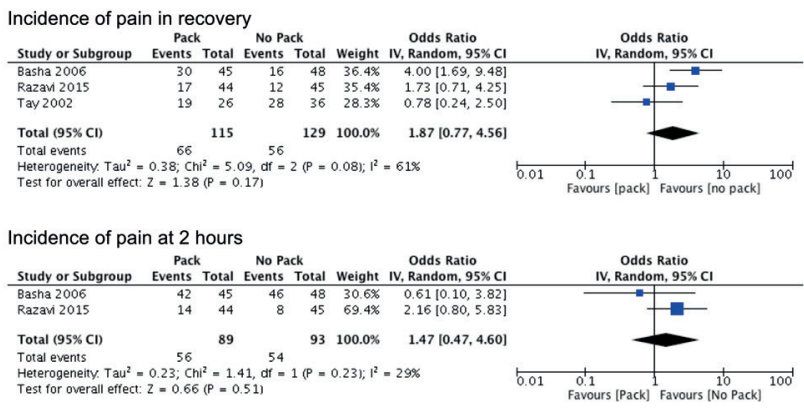

Incidence of pain at 6 hours
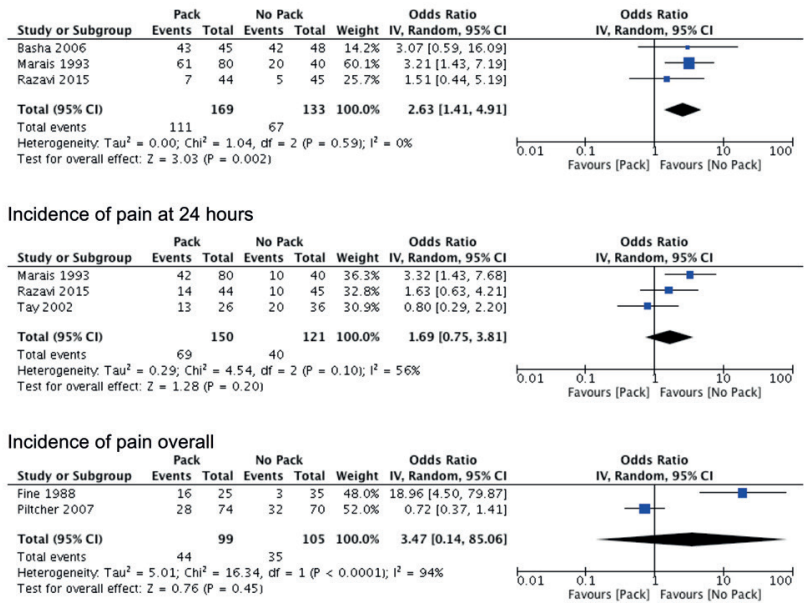

Figure 3. Meta-analysis of incidence of post-operative pain.

on their subjective self-assessment. There was no significant difference between groups $p=0.63$ (Table 4$)^{(12)}$.

\section{Adverse events}

No study reported any significant adverse events associated with throat pack use. In particular, there were no instances of retention or ingestion of packs.

\section{Discussion}

\section{Summary of main results}

This is the largest systematic review to date on the subject of throat pack use and highlights a lack of evidence that throat packs are of benefit in ENT, oral and dental surgery. In addition, it has highlighted a paucity of consistency and quality in research in this area, which merits discussion.

\section{Overall completeness and applicability of evidence}

Of the 13 studies included, only one showed a benefit from the use of throat packs. Green et al showed throat pain to be worse at 24 hours in patients in whom a pack was not used. The mean severity in the non-pack group was 1.83 on the Wong-Baker Faces scale, vs 0.3 in the packed group ${ }^{(17)}$. Whilst statistically significant, the clinical significance is dubious, as in both groups average pain was less than 'hurts a little bit'. There were no clear differences between Green et al. and other studies to explain this finding - the surgery, pack type and demographics were unremarkable. Analgesia post-operatively was not studied, so there may have been variation between groups.

Four studies showed significantly more throat pain with throat pack use and one showed significantly higher incidence of aphthous stomatitis after throat pack use. This can be explained by the trauma of insertion and removal causing small abrasions ${ }^{(20)}$. Five studies did not show a significant difference in throat pain between groups - this may have been due to better analgesia use as three studies reported clear multimodal analgesic use $(14,15,19)$, which was not fully reported in the other papers using pain as an outcome.

Historically, a key indication for a throat pack use is for the prevention of PONV. This review found no evidence to support this hypothesis. This may be due to the routine, intra-operative use of anti-emetics, and the high efficacy of modern drugs, which were given intra-operatively in all but one study ${ }^{(22)}$.

Potential biases in review

Studies included were reviewed by two authors independently with majority of studies using Cochrane Collaborations 'Risk of Bias' tool (10) (Figure 1). There were significant amounts of unclear bias risk, which limits the strength of conclusions drawn in this review.

In common with a previous review ${ }^{(24)}$, this study is limited by methodological flaws of the included trials. Variation in the type of pack, outcome measures and time points at which outcomes were assessed led to heterogenous data. Reporting of pack insertion method was variable, although the majority appeared to be inserted by anaesthetists. Anaesthesia, analgesia and antiemetic use were inconsistently reported. It should be noted that there is a major limitation from the small sample sizes as this limits the capture of the rare adverse events associated with throat packs ${ }^{(2)}$. Most serious complications from throat packs are not written up, with the result that there is likely to be publication bias that weakens our ability to understand how throat packs can have a negative effect. Furthermore, the total number of patients included in this systematic review remains relatively low, which may limit how generalizable the findings are to the broader patient population. Further, larger prospective studies are the only way in which this could be overcome.

At a review level, a major limitation was the difficulty in contacting authors to clarify information and seek data. Despite repeated efforts, replies were not forthcoming, probably due to the years elapsed since many of the studies were published.

This is the largest review to date looking at the use of throat 
packs in dental, oral and ENT surgery. Athanassoglou et al. ${ }^{(2)}$ performed a recent review of good quality on a similar topic however this was limited to the Medline database and publications of any type. The conclusion from this review is discussed further below.

Implications for clinical practice and research

Throat pack use in ENT surgery is predominately for rhinology operations. The utilisation of topical vasoconstrictor agents, the establishment of endoscopic techniques in sinus surgery and hypotensive anaesthetic practice have contributed to reduced intraoperative bleeding. Furthermore, laryngeal mask airway devices are increasingly used in endoscopic sinus surgery and can prevent ingestion of blood and secretions due to its position above the oesophageal inlet ${ }^{(24)}$. These advances in nasal surgery drastically limit the indication for throat packs.

Despite implementation of a protocol regarding management of throat pack by the National Patient Safety Agency, and its inclusion on the WHO surgical safety checklist, the risk of retained throat packs is high ${ }^{(1)}$ and there have been several incidents in the UK in recent years ${ }^{(7)}$. Retention of throat packs post operatively after extubation risks significant patient morbidity and mortality by airway obstruction or ingestion into the stomach requiring retrieval by endoscopy ${ }^{(25)}$.

Given the lack of controlled trial evidence of benefit from using throat packs, and the potential risk associated with retention, there is an argument for discontinuing their routine use in ENT and oral surgery cases. This agrees with suggestions from a recent review and joint consensus statements (Difficult Airway
Society (DAS), the British Association of Oral and Maxillofacial Surgery (BAOMS) and the British Association of Otorhinolaryngology, Head and Neck Surgery (ENT-UK)) which advised that the insertion of throat packs by anaesthetists should no longer be routine, and only considered in cases where it is deemed essential after discussion between anaesthetic and surgical teams $s^{(2)}$.

\section{Conclusion}

This review provides no evidence in support of a clinical benefit from throat packs and finds evidence of increased throat pain when they are used. Although there may be specific cases and reasons that justify the use of a throat pack, including clinical experience, the findings from this review support the proposal that there is no clear indication for their routine use in ENT, maxillofacial and dental procedures.

\section{Acknowledgements}

David J Vaughan ${ }^{3}$ for giving his expertise and advice. Dr Rajinder Singh Chaggar for reviewing the final manuscript. No funding was provided for this study.

\section{Authorship contribution}

AN and CA designed the study. CA ran the searches. CA, YP, $A N$ and $M R$ determined study inclusion/exclusion criteria and extracted data. CA, YP and AN performed data analysis. CA, YP, AN, MR and AS wrote the manuscript.

\section{Conflict of interest}

The authors have no conflicts of interest to declare.

\section{References}

1. Oliveira MC, Tufik S, Haddad FL, Santos-1. Bisase B, Matthews NS, Lan C. Current practice and opinions regarding the use of oropharyngeal throat packs in the United Kingdom. J Patient Saf. 2011 Sep;7(3):162-4.

2. Athanassoglou V, Patel A, McGuire $B$, et al. Systematic review of benefits or harms of routine anaesthetist-inserted throat packs in adults: practice recommendations for inserting and counting throat packs: An evidence-based consensus statement by the Difficult Airway Society (DAS), the British Association of Oral and Maxillofacial Surgery (BAOMS) and the British Association of Otorhinolaryngology, Head and Neck Surgery (ENT-UK). Anaesthesia. 2018 May;73(5):612-8.

3. Knepil GJ, Blackburn CW. Retained throat packs: results of a national survey and the application of an organisational accident model. Br J Oral Maxillofac Surg. 2008 Sep 1;46(6):473-6.

4. Alvi N. A Survey about Throat Pack
Management in Perioperative Period. Journal of Anesthesia \& Clinical Research [Internet]. 2016 [cited 2018 Oct 12];7(9). Available from: https://www.omicsonline. org/open-access/a-survey-about-throatpack-management-in-perioperative-period-2155-6148-1000664. php?aid=80164

5. Colbert S, Jackson M, Turner M, et al. Reducing the risk of retained throat packs after surgery. Br J Oral Maxillofac Surg. 2012 Oct 1;50(7):680-1.

6. Najjar MF, Kimpson J. A Method for Preventing Throat Pack Retention. Anesth Analg. 1995 Jan;80(1):208.

7. Never Events data | NHS Improvement [Internet]. [cited 2018 Aug 8]. Available from: https://improvement.nhs.uk/resources/never-events-data/

8. PRISMA [Internet]. [cited 2018 Jul 31]. Available from: http://prisma-statement. org/PRISMAStatement/FlowDiagram.aspx

9. Cochrane Handbook for Systematic Reviews of Interventions [Internet]. [cited 2018 Jul 31]. Available from: http://hand- book-5-1.cochrane.org/

10. Assessing Risk of Bias in Included Studies | Cochrane Bias [Internet]. [cited 2018 Jul 31]. Available from: /bias/assessing-risk-biasincluded-studies

11. Tay JYY, Tan WKS, Chen FG, et al. Postoperative sore throat after routine oral surgery: influence of the presence of a pharyngeal pack. Br J Oral Maxillofac Surg. 2002 Feb;40(1):60-3.

12. Fine J, Kaltman S, Bianco M. Prevention of sore throat after nasotracheal intubation. J Oral Maxillofac Surg. 1988 Nov;46(11):9467.

13. Marais J, Prescott RJ. Throat pain and pharyngeal packing: a controlled randomized double-blind comparison between gauze and tampons. Clin Otolaryngol. 1993 Oct;18(5):426-9.

14. Piltcher O, Lavinsky M, Lavinsky J, et al. Effectiveness of hypopharyngeal packing during nasal and sinus surgery in the prevention of PONV. Otolaryngol Head Neck Surg. 2007 Oct;137(4):552-4. 
15. Fennessy BG, Mannion S, Kinsella JB, et al. The benefits of hypopharyngeal packing in nasal surgery: a pilot study. Ir J Med Sci. 2011 Mar;180(1):181-3.

16. Razavi M, Gilani MT, Bameshki AR, et al. Pharyngeal Packing during Rhinoplasty: Advantages and Disadvantages. Iran J Otorhinolaryngol. 2015 Nov; 27(83): 423 428.

17. Green R, Konuthula N, Sobrero M, et al. Use of pharyngeal packs in functional endoscopic sinus surgery: A randomized controlled trial: Use of Pharyngeal Packs in FESS. Laryngoscope. 2017 Nov;127(11):2460-5.

18. Basha SI, McCoy E, Ullah R, et al. The efficacy of pharyngeal packing during routine nasal surgery? a prospective randomised controlled study. Anaesthesia. 2006 Dec;61(12):1161-5.

19. Meco BC, Ozcelik M, Yildirim Guclu C, et al Does Type of Pharyngeal Packing during
Sinonasal Surgery Have an Effect on PONV and Throat Pain? Otolaryngol Head Neck Surg.2016 Apr;154(4):742-7.

20. Erkalp K, Korkut YA, Meric A, et al. Pharyngeal packing is a predisposing factor for postoperative aphthous stomatitis in nasal surgery. Otolaryngol Head Neck Surg.2010 May;142(5):672-6.

21. Korkut AY, Erkalp K, Erden V, et al. Effect of pharyngeal packing during nasal surgery on postoperative nausea and vomiting. Otolaryngol Head Neck Surg. 2010 Dec;143(6):831-6.

22. Al-Lami A, Amonoo-Kuofi K, Kulloo P, et al. A study evaluating the effects of throat packs during nasal surgery: a randomised controlled trial. Eur Arch Otorhinolaryngol. 2017 Aug;274(8):3109-14.

23. Seraj M., Ankutse M., Khan F, et al. Tracheal Soiling with Blood During Intranasal Surgery. Middle East
Anesthesiol.1991;11(1):79-89.

24. Jaiswal V, Bedford GC. Review of the use of throat packs in nasal surgery. J Laryngol Otol. 2009 Jul;123(07):701.

25. Baranger $V$, Bon Mardion N, Dureuil B, et al. Human Error in Throat Pack Management: Report of Two Cases. A Case Rep. 2016 Jun 15;6(12):397-8.

Miss Caroline Anderson

Department of ENT Surgery

Wexham Park Hospital

Slough

United Kingdom

E-mail: C.anderson@doctors.org.uk.

This paper contains supplementary materials online: at www.rhinologyjournal.org 


\section{SUPPLEMENTARY INFORMATION}

\section{Appendix 1. Search strategies.}

\section{Medline}

1. exp Pharynx/ or pharyn*.mp.

2. oropharyn*.mp. or exp Oropharynx/

3. nasopharyn*.mp. or exp Nasopharynx/

4. exp Hypopharynx/ or hypopharyn*.mp.

5. throat.mp.

6. pack*.mp.

7. 1 or 2 or 3 or 4 or 5

8. 6 and 7

9. randomized controlled trial.pt.

10. controlled clinical trial.pt.

11. randomized.ab.

12. placebo.ab.

13. drug therapy.fs.

14. randomly.ab.

15. trial.ab.

16. groups.ab.

17. 9 or 10 or 11 or 12 or 13 or 14 or 15 or 16

18. exp animals/ not humans.sh.

19. 17 not 18

20. 8 and 19

\section{Embase}

1. throat.mp. or exp throat/

2. exp pharynx/ or pharyn*.mp.

3. exp oropharynx/ or oropharyn*.mp.

4. nasopharyn*.mp. or exp nasopharynx/

5. exp hypopharynx/ or hypopharyn*.mp.

6. pack* $^{*} . \mathrm{mp}$.

7. 1 or 2 or 3 or 4 or 5

8. 6 and 7

9. crossover-procedure/ or double-blind procedure/ or randomized controlled trial/ or single-blind procedure/ or (random* $^{*}$ or factorial* or crossover* or cross over* or placebo* or (doubl* adj blind*) or (singl* adj blind*) or assign* or allocat* or volunteer*).tw.

10. 8 and 9

\section{CENTRAL}

1. Pharyn*

2. Pack*

3. Oropharyn*

4. Nasopharyn*

5. Hypopharyn*

6. 1 or 3 or 4 or 5

7. 6 and 2 